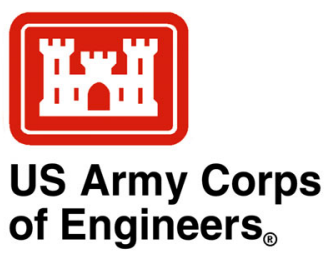

\title{
Comparison of Predicted and Measured Shoaling at Morro Bay Harbor Entrance, California
}

\author{
by Edward F. Thompson, Inocencio P. DiRamos, \\ and Robert R. Bottin, Jr.
}

PURPOSE: This Coastal and Hydraulics Engineering Technical Note (CHETN) summarizes comparisons of predicted and measured shoaling at Morro Bay Harbor Entrance, California. Shoaling predictions were determined by the U.S. Army Engineer District, Los Angeles, as part of the navigation improvements Feasibility Report (USAED, Los Angeles, 1991). Prototype survey data were collected in pre- and postdredge surveys and during a monitoring effort at the site that was conducted as part of the Monitoring Completed Navigation Projects (MCNP) Program. Validation of design procedures used to predict shoaling with prototype data increases confidence levels in design tools for future applications.

BACKGROUND: Morro Bay Harbor is located on the central coast of California about midway between Los Angeles and San Francisco. The harbor is protected from the effects of the open ocean by a Federal navigation project consisting of two permeable, rubble-mound breakwaters, an inner harbor groin, and a stone revetment. The navigation channel commences at the gap formed by the outer breakwaters and extends through a bay via three channel reaches. An aerial view of the harbor entrance is shown in Figure 1.

Prior to the latest entrance channel improvements, the entrance to Morro Bay Harbor was known as one of the most dangerous in the United States with numerous injuries, deaths, and vessel damages occurring due to steep and breaking wave conditions in the entrance. Entrance problems experienced were due to a combination of exposure to storm wave conditions and bathymetry in the entrance. A feasibility study (USAED, Los Angeles, 1991) considered a wide array of navigation improvements. Since structural alternatives lacked economic justification, channel modifications, which were expected to allow large waves to pass through the entrance without steepening and breaking, were selected for the design (USEAD, Los Angeles, 1994). In December 1995, entrance channel improvements were completed that consisted of construction of a deepened, expanded entrance channel (Figure 2). The authorized depth increased from $-4.9 \mathrm{~m}(-16 \mathrm{ft})$ to $-9.1 \mathrm{~m}(-30 \mathrm{ft})$. Additionally, the plan provided for advanced maintenance dredging to a depth of $-12.2 \mathrm{~m}(-40 \mathrm{ft})$.

PREDICTED DESIGN PERFORMANCE: Shoaling patterns and rates at the modified Morro Bay Harbor Entrance were predicted by the Los Angeles District based on numerical/theoretical Los Angeles District investigations, past dredging experience, prototype data from a preproject test trench dredged and monitored by the Los Angeles District (USAED, Los Angeles, 1991), and a U.S. Army Engineer Research and Development Center physical model study (Bottin 1993). Predicted shoaling rate for the final design was $183,500 \mathrm{cu} \mathrm{m} /$ year $(240,000 \mathrm{cu}$ yd/year), or $15,300 \mathrm{cu} \mathrm{m} /$ month $(20,000 \mathrm{cu} \mathrm{yd} / \mathrm{month})$, with a 3 -year maintenance cycle. 
ERDC/CHL CHETN-IV-45

June 2002

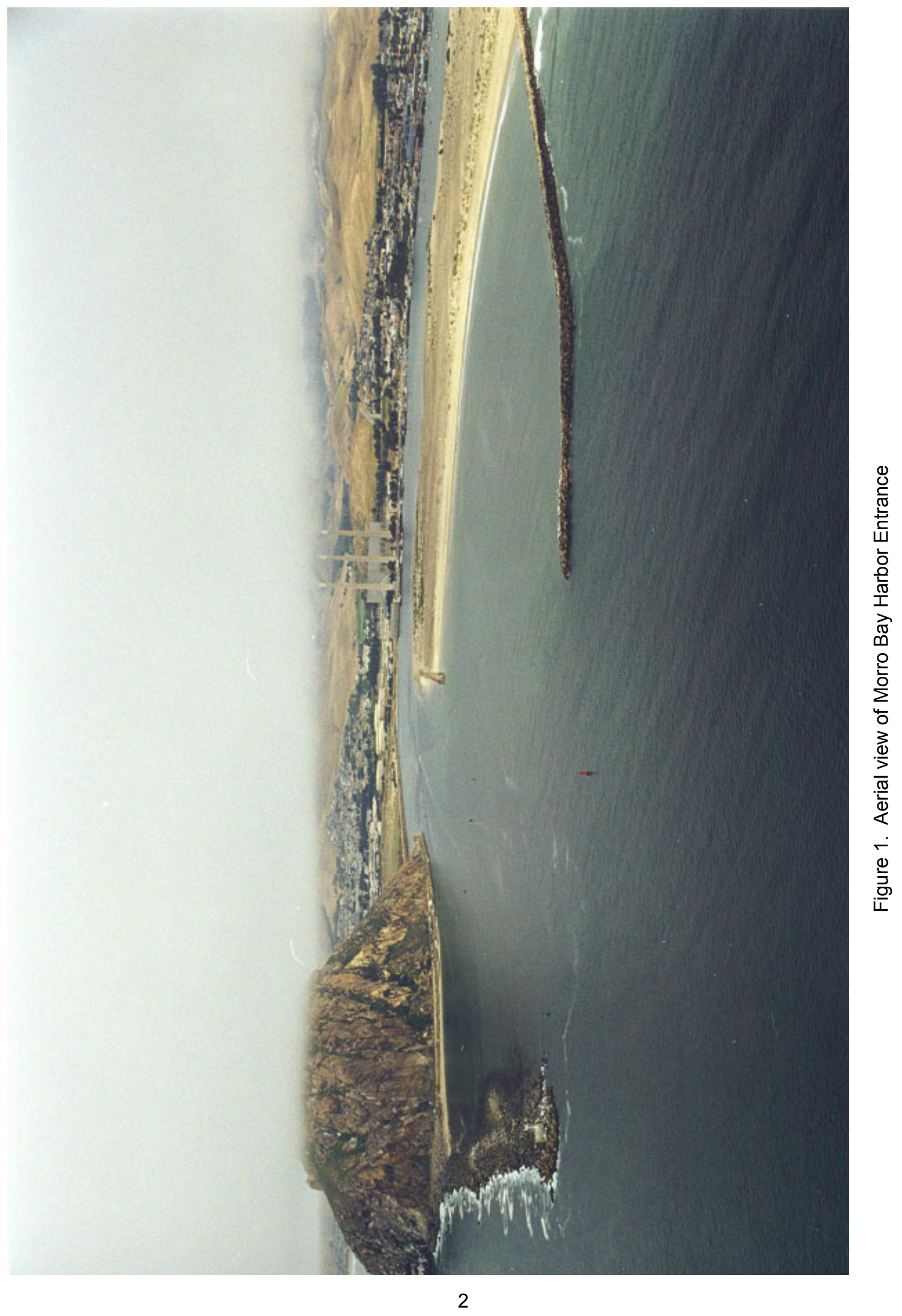




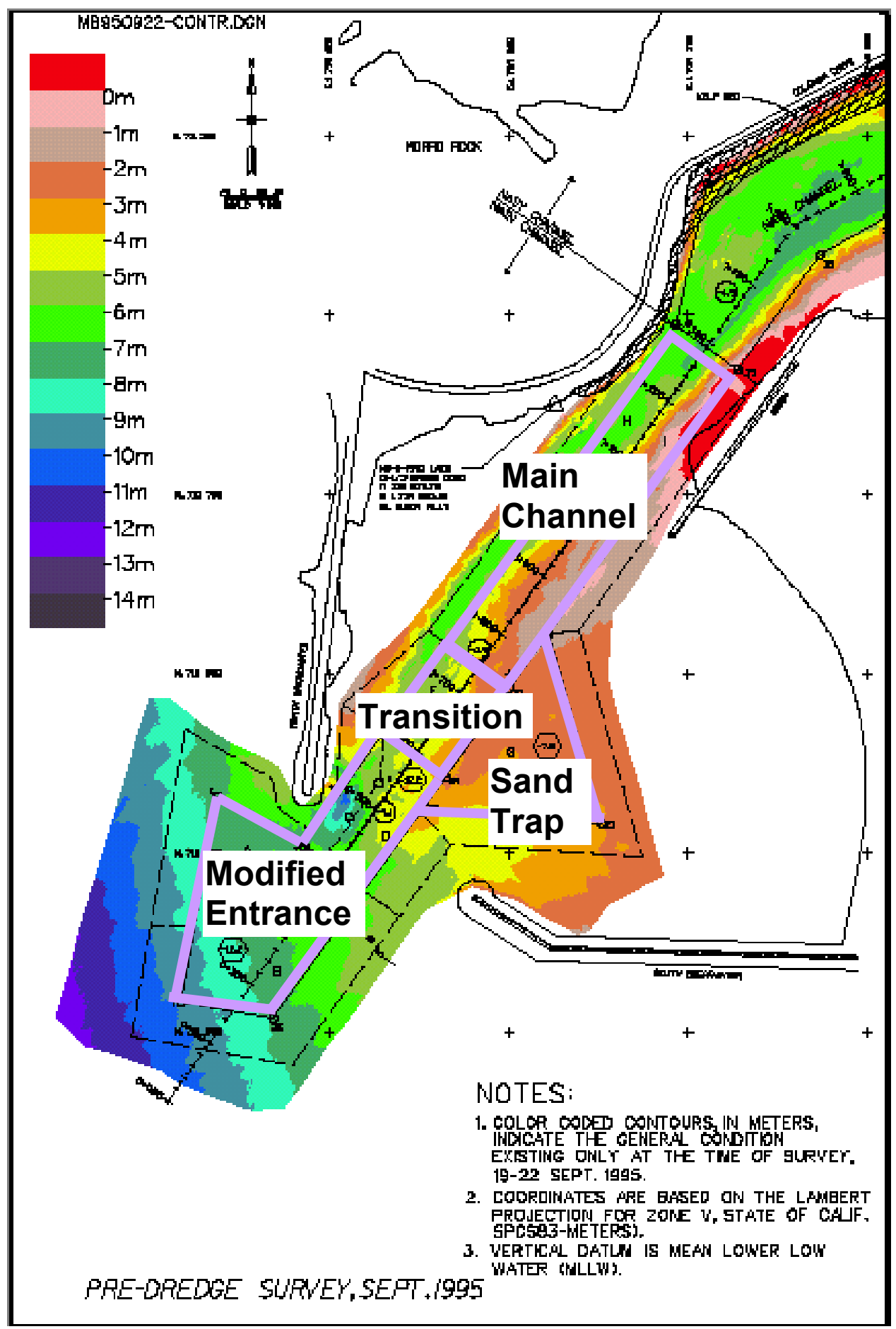

Figure 2. Location of project components

PROTOTYPE DATA: Bathymetry surveys of the Morro Bay project and adjacent areas were conducted 11 times between January 1998 and August 2001. An additional seven surveys were conducted prior to the start of the MCNP monitoring project. These bathymetric data collected since initial dredging of the modified entrance and transition area provide a valuable record of shoaling rates and patterns. 
To quantify bottom changes, the dredged project area was divided into nine segments (Figure 3). For areas A through F, several measures of bottom change were used to capture different aspects of project response to dredging. For presentations in this CHETN, the method for calculating available materials in these areas is defined in Figure 4. The volume of available materials was calculated from each survey for each area.

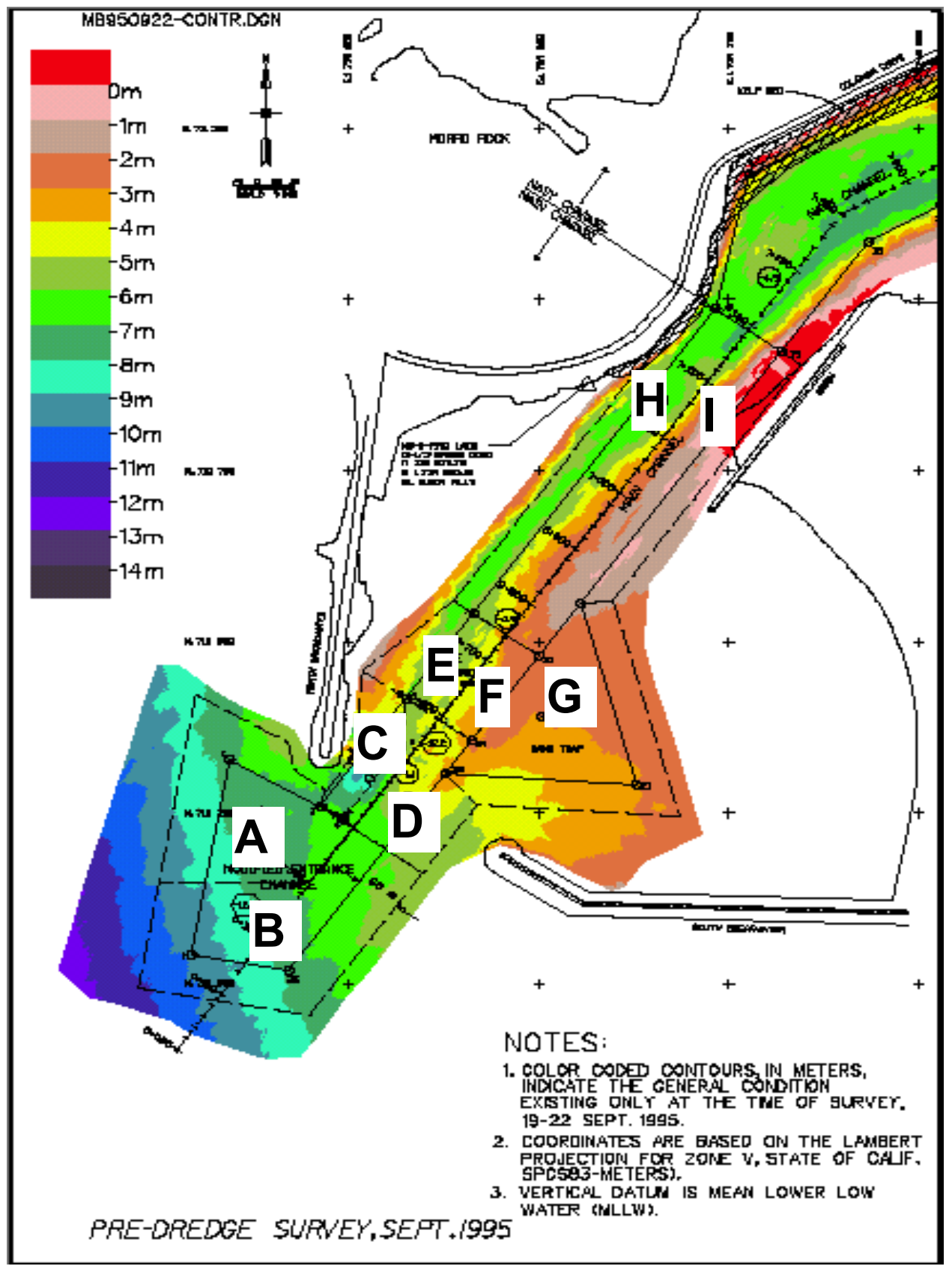

Figure 3. Definition of prototype areas for quantifying shoaling rate 


\section{First Survey}

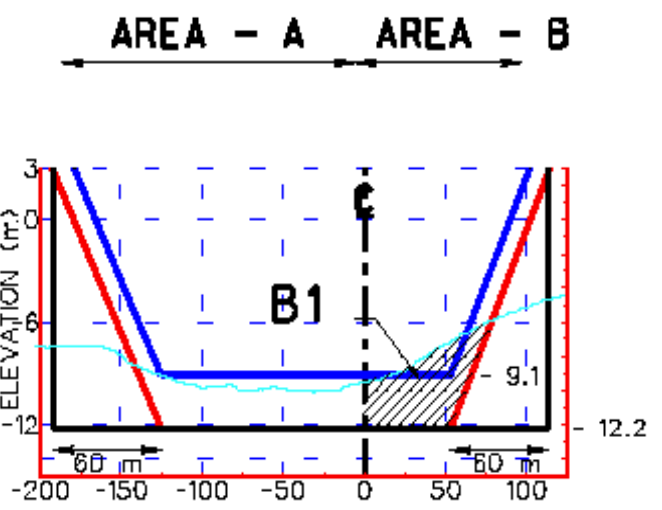

\section{Second Survey}
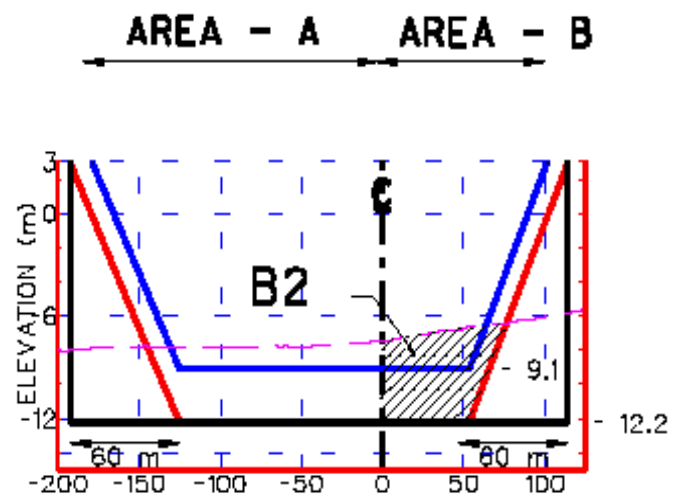

\section{Volume Change at $-12.2 \mathrm{~m}$}

\section{B1 and B2 are available materials in Area B Difference between B2 and B1 is volume change between surveys}

Figure 4. Definition sketch of method for calculating available materials and volume change

The volume of available materials provides a useful, easily understood measure of the amount of sediment stored in the dredged project areas. This volume varies with time due to deposition, scour, and dredging. Variation in available material volume with time over the length of the monitoring project is summarized in Figure 5. Values shown for the modified entrance are the sum of available materials for areas A, B, C and D. Values for the transition are the sum of available materials for areas $\mathrm{E}$ and F. Sand trap values are for Area $\mathrm{G}$ and main channel values are the sum for areas $\mathrm{H}$ and I.

The volume of available materials is greater for the modified entrance than for other areas during most of the 6-year time period. The second largest volume is generally in the sand trap. The volume stored in the modified entrance also varies more dramatically with time than for other areas. Variations represent increases due to natural shoaling punctuated by sharp decreases due to periodic dredging. The volume of materials in the main channel also shows cycles of shoal buildup and dredged removal. Such cycles are not evident in the sand trap, because most dredging episodes did not address that area. The sand trap filled and remained filled during most of the monitoring period.

Storms can cause major shoaling, especially in the entrance. Storm-induced shoals are then gradually redistributed over time throughout the project area. Thus, the total volume of available materials in the dredged project area is probably a more accurate measure of long-term shoaling induced by coastal waves and currents. Total volume is also shown in Figure 5. Total volume during the entire monitoring period is less than the preproject volume of 713,000 cu m in September 95. Total volume reached its maximum value, around 630,000 cu m, during the winter 1998 storm season. 
ERDC/CHL CHETN-IV-45

June 2002

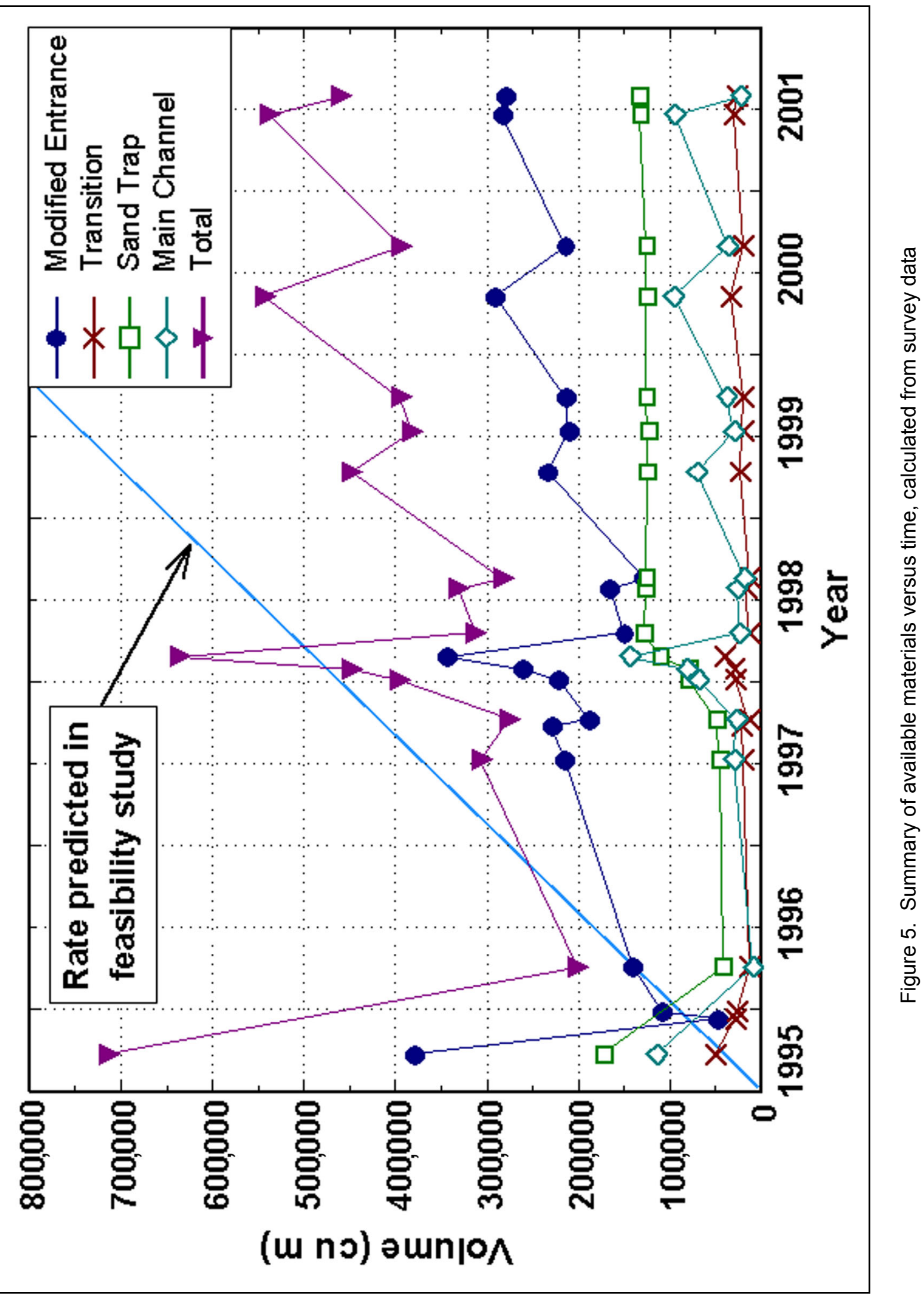


Bottom changes between successive surveys provide data for bathymetric change analysis. Eight survey intervals, generally those unaffected by dredging in entrance and transition areas, were selected for bathymetric analysis. Intervals were numbered sequentially for convenient reference. Survey intervals represent time periods ranging from 1 to 15 months. Differences in available materials between successive surveys were calculated to give volume changes and shoaling rates over each survey interval (Figure 6). Wave conditions characterizing each survey interval vary from mild summer waves to intense storms to the full range of seasons.

During survey intervals encompassing winter months, shoaling occurs in the modified entrance, transition, sand trap, and main channel areas. During survey intervals covering predominantly summer months, bathymetric change is slight in most areas. Areas consistently prone to shoaling include the entrance and transition areas and the east side of the main channel along the outer part of the groin. Shoaling rate data indicate that shoaling preferentially affects the south portion of the channel in the transition area and often in the modified entrance, as well. The data show evidence of severe storms blanketing the modified entrance with 1-2 $\mathrm{m}$ (3.3-6.6 ft) of sediment from the south and scouring around the north breakwater head. Severe storms also appear to result in a sediment deposition of $2 \mathrm{~m}(6.6 \mathrm{ft})$ or more in the mid and upper part of the main channel. Patterns over the longer survey intervals suggest that shoals built during stormy periods are gradually redistributed by waves and currents.

Shoaling rates calculated from survey data are influenced by seasons represented in the survey interval. They may also be influenced by interval length, since shoaling rates may tend to be elevated immediately after dredging as material is more effectively trapped in deep excavation areas. The importance of these influences on the Morro Bay Harbor data is shown in Figure 6. Shoaling rate clearly diminishes with increasing survey interval length. Seasonal effects are dramatic. Survey interval No. 3, an intense winter storm interval, produced shoaling rates an order of magnitude greater than for most other intervals. Survey interval No. 8, a summer interval, produced the lowest shoaling rate, despite its being one of the shortest survey intervals immediately following entrance dredging. The longest survey interval (No. 1) produced the lowest shoaling rate among nonsummer intervals.

COMPARISON OF PREDICTED AND MEASURED SHOALING RATES: Shoaling rate predicted by USAED, Los Angeles (1991) in the project feasibility study is illustrated by a sloped line superimposed on the volume time-histories (Figure 5). The slope of this line is remarkably similar to slopes of total volume accumulation between dredging cycles during 1998-2001.

Prototype shoaling rates in Figure 6 are generally comparable to or higher than the Los Angeles District-predicted rate, except for the two summer intervals and the longest interval (No. 1). The average overall survey intervals shown, taking into account interval length, is $19,300 \mathrm{cu} \mathrm{m} / \mathrm{month}$. This shoaling rate is about 20 percent higher than the rate predicted in the feasibility study. Over intervals of more than 6 months, shoaling rates are remarkably close to the predicted rate. The 15.4 months encompassed by survey interval No. 1, the longest interval, include a disproportionate number of summer months and that can be expected to make the shoaling rate unrepresentatively low. 


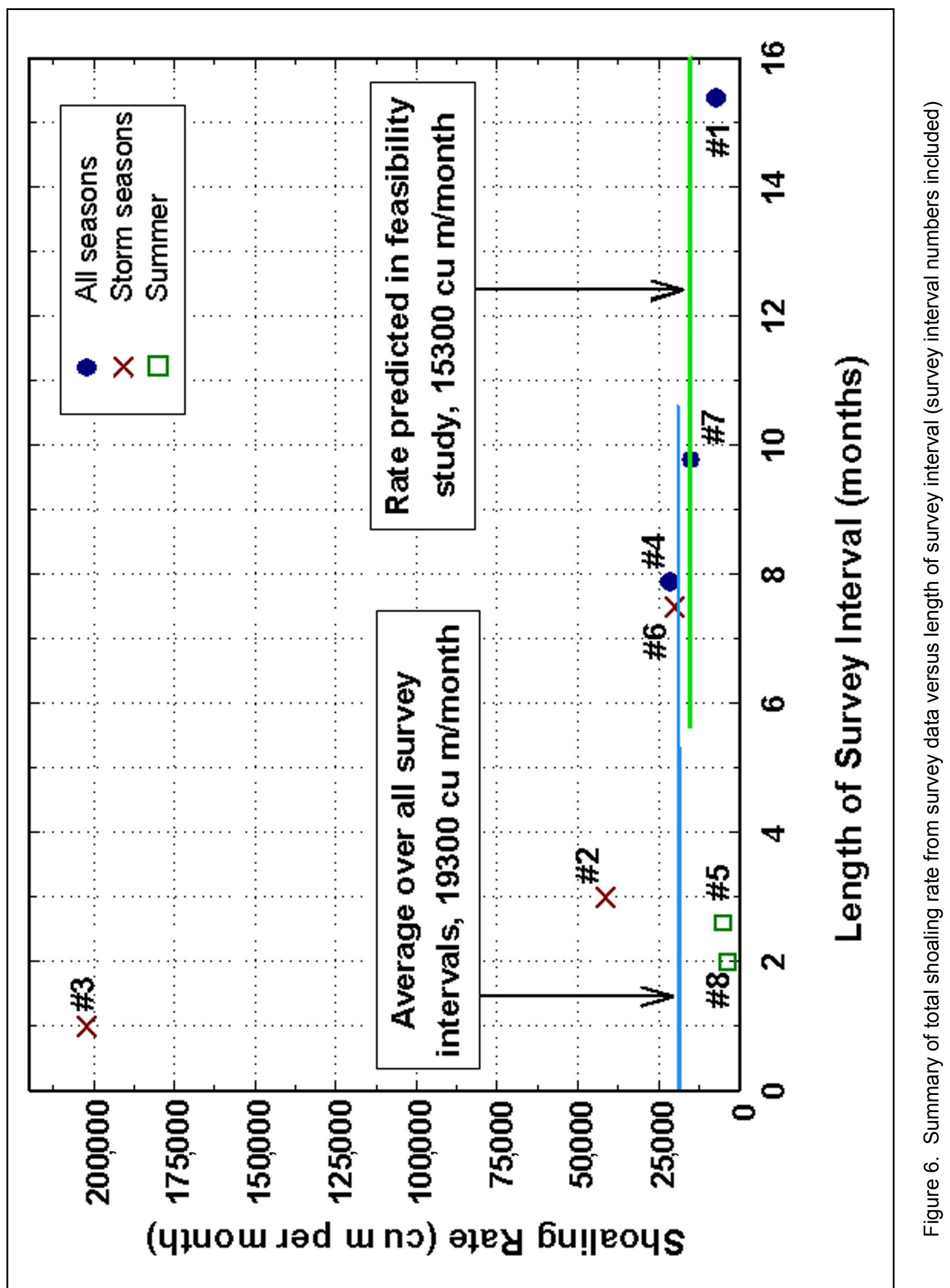


Incident wave climate information can be helpful in analyzing bathymetric changes determined from survey data. Although linkages between incident waves and sediment transport and trapping around Morro Bay Harbor Entrance are complex and poorly understood, incident waves clearly provide a major forcing. The time-history of incident wave significant height, period, and direction was processed to estimate nearshore breaking wave parameters and potential wave-driven longshore sediment transport. Calculated potential longshore transport rate time-histories were summed to give potential longshore transport volumes over each survey interval. A standard equation was used for the calculations, as follows:

$$
Q=K H_{b s}{ }^{5 / 2} \sin \left(2 \alpha_{b}\right)
$$

where

$Q=$ potential longshore transport rate

$K=$ constant

$H_{b s}=$ significant wave height at breaking

$\alpha_{b}=$ breaking wave angle relative to bottom contours

When $H_{b s}$ is in meters and $Q$ in cu $\mathrm{m} /$ day, the traditional value of $K$ is 5,100 . Several recent studies applying the equation as in this study have found that this value of $K$ overestimates longshore transport rates relative to field experience and a value of $K=1,987$ is more appropriate (e.g., Cialone and Thompson 2000). The lower value of $K$ was also used in this study.

Potential gross longshore transport volumes, $Q_{g}$, computed from wave time-histories can be compared to volume changes from survey data (Figure 7). Survey interval No. 8 is not shown due to wave data unavailability. For the two shortest nonsummer survey intervals (No. 2 and No. 3), the total volume change from survey data equals or exceeds $Q_{g}$. This suggests that 100 percent of the gross longshore transport was captured in the newly-dredged project during these two stormy survey intervals. For longer survey intervals, total volume change is less than one-third of the potential gross longshore transport volume. The data suggest that, over time intervals on the order of 1 year, around 15-30 percent of the gross longshore transport may be retained in the dredged project.

Potential longshore transport volumes are also helpful for giving a perspective on the anomalous volume changes calculated during February 1998 (survey interval No. 3). Potential $Q_{g}$ volume for this 1-month interval is comparable to that for survey interval No. 2, a 3-month interval during fall and early winter of the same year. Intensified storm activity indicated during the winter of 1997-8 may be attributed to the presence of El Nino this year. Potential $Q_{g}$ volumes for longer survey intervals are considerably larger than for the winter of 1997-8, suggesting that the net effect of this winter is reasonably consistent with other years.

When volume change from each interval of survey data is divided by the calculated $Q_{g}$ for the interval and converted to percent, prototype shoaling can be better related to wave conditions. This percentage of $Q_{g}$ trapped in the dredged project area tends to decrease as interval length increases (Figure 8). Results suggest that the project traps all of the gross longshore transport immediately 


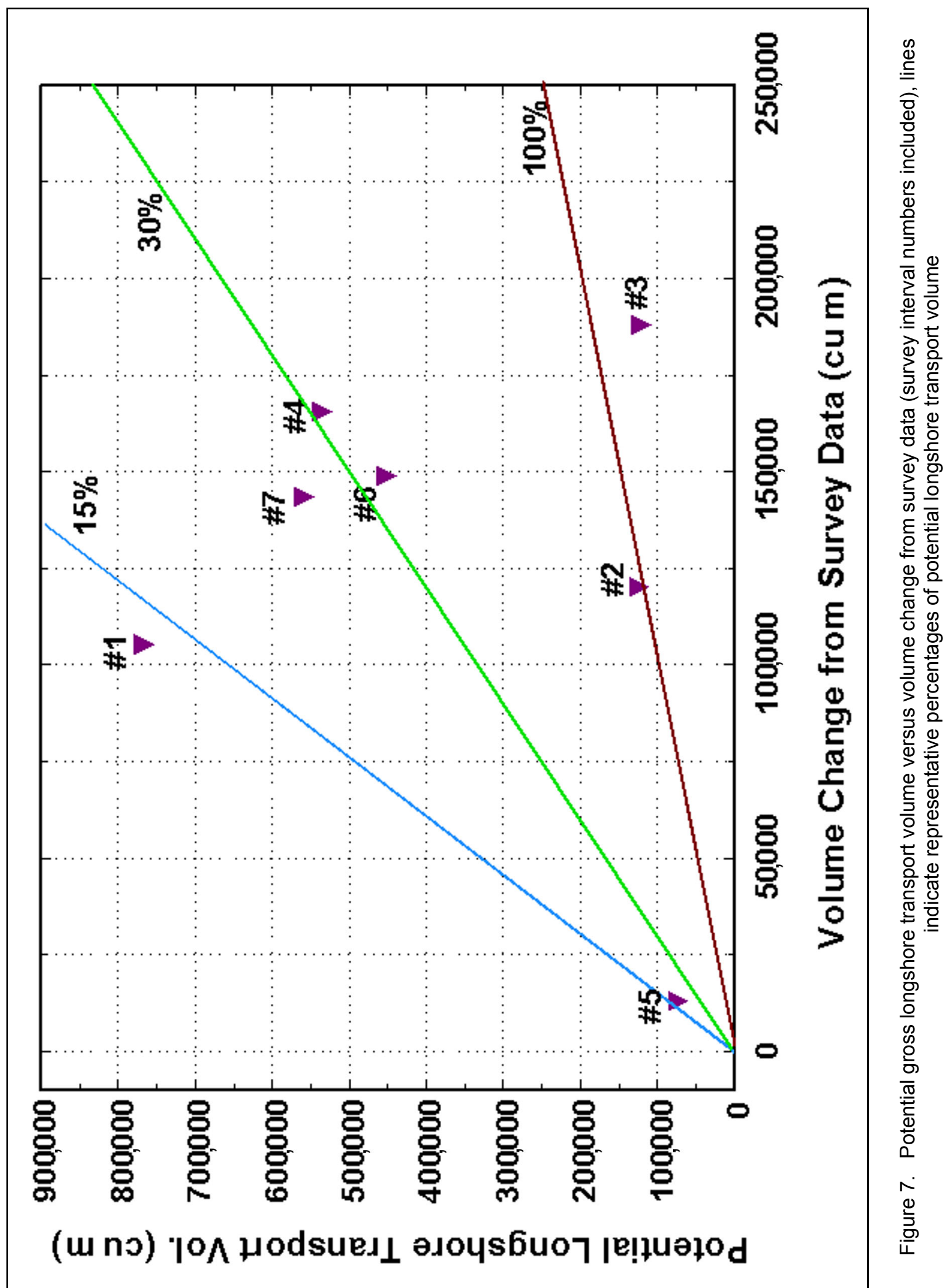




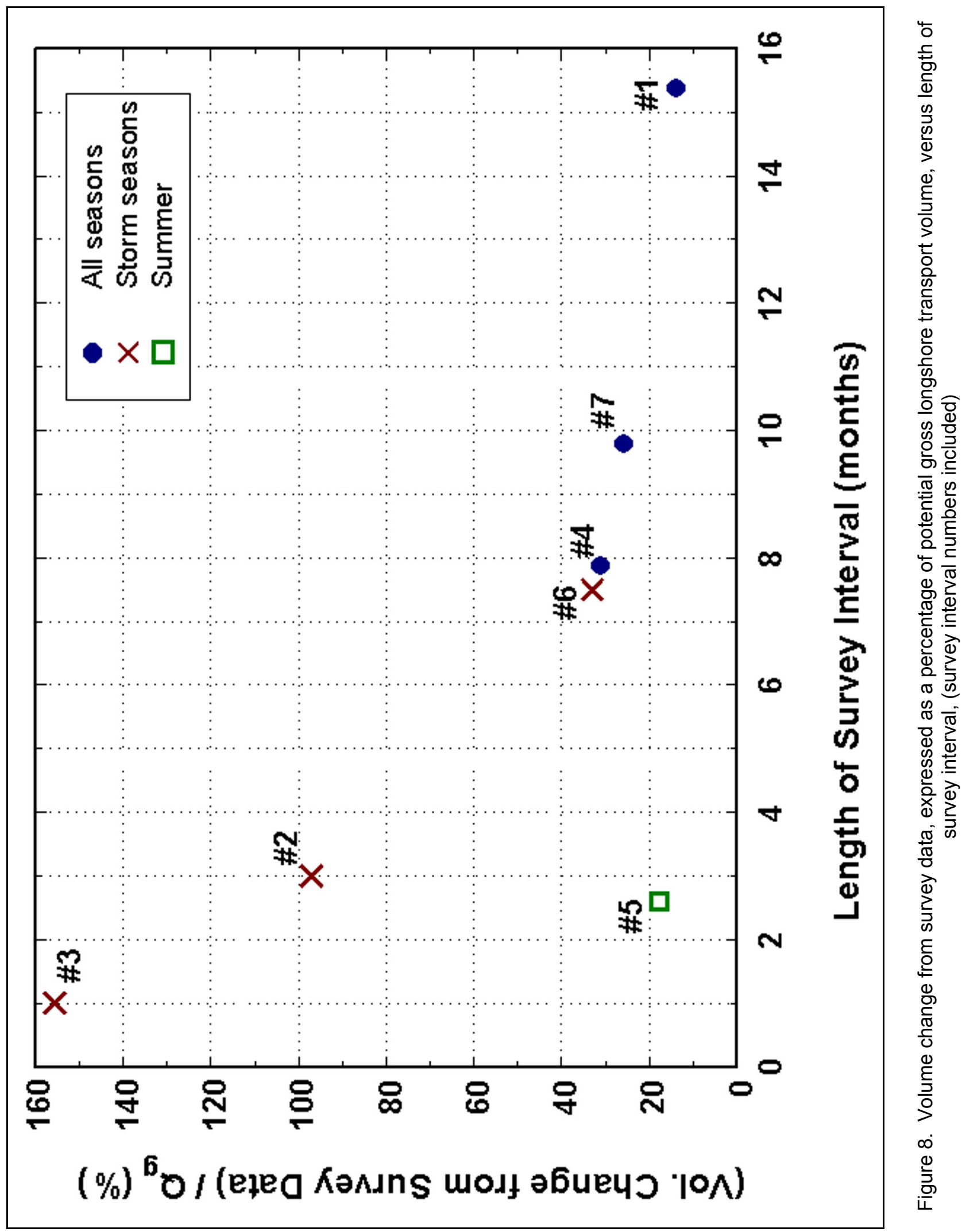


after dredging. As shoaling progresses, a decreasing percentage of $Q_{g}$ is trapped in the project area, dropping to about 20-30 percent of $Q_{g}$ after 1 year.

SUMMARY: Predicted shoaling rate and maintenance dredging requirements were a critical component of designing the modified entrance to Morro Bay Harbor to alleviate dangerous breaking wave conditions. Shoaling rates for a complex entrance environment are not easily estimated, and the Los Angeles District used a variety of tools to arrive at the design prediction. Postproject prototype measurements of bottom changes have provided valuable documentation of shoaling rates and patterns. Available data indicate that the Los Angeles District prediction of shoaling rate was quite accurate.

ADDITIONAL INFORMATION: Questions relative to this CHETN may be addressed to Dr. Edward F. Thompson at (601-634-2027), FAX (601-634-3433), or e-mail: thompse@wes.army.mil or, Mr. Robert R. Bottin, Jr., at (601-634-3827),FAX (601-634-4827), or email: bottinr@wes.army.mil. More detailed information on this subject may be obtained from (Thompson, Bottin, and Shak 2002). Additional information on the MCNP Program may be obtained from the MCNP Web site at: http://chl.wes.army.mil/research/navigation/mcnp_site/ default.htm. This technical note should be cited as follows:

Thompson, E. F., DiRamos, I. P., and Bottin, R. R., Jr. (2002). "Comparison of predicted and measured shoaling at Morro Bay Harbor Entrance, California," ERDC/CHL CHETN-IV-45, U.S. Army Engineer Research and Development Center, Vicksburg, MS. http://chl.wes.army.mil/library/publications/chetn/

\section{REFERENCES}

Bottin, R. R., Jr. (1993). "Design for entrance channel navigation improvements, Morro Bay Harbor, Morro Bay, California," Technical Report CERC-93-2, U.S. Army Engineer Waterways Experiment Station, Vicksburg, MS.

Cialone, M. A., and Thompson, E. F. (2000). "Wave climate and littoral sediment transport potential, Long Beach Island, New Jersey,” Technical Report ERDC/CHL TR-00-21, U.S. Army Engineer Research and Development Center, Vicksburg, MS.

Thompson, E. F., Bottin, R. R., Jr., and Shak, A. T. (in preparation). "Monitoring of entrance channel improvements at Morro Bay Harbor, Morro Bay, California; Monitoring Completed Navigation Projects Program," Technical Report ERDC/CHL TR-02-xx, U.S. Army Engineer Research and Development Center, Vicksburg, MS.

U.S. Engineer District, Los Angeles. (1994). "Design memorandum for navigation improvements; Morro Bay Harbor, San Luis Obispo County, CA,” Los Angeles, CA.

U.S. Army Engineer District, Los Angeles (1991). "Feasibility report; Morro Bay Harbor, San Luis Obispo County, CA," 2 Vol, Los Angeles, CA. 